\title{
CULTURA CIGANA: A PRÁTICA DO NOMADISMO E A CONCRETIZAÇÃO DO DIREITO À MORADIA
}

\author{
Rayssa Rodrigues Meneghetti* \\ Carla Ribeiro Volpini Silva**
}

\begin{abstract}
RESUMO: O presente artigo visa analisar o histórico e os aspectos gerais acerca da Cultura dos povos ciganos, sobretudo a prática do nomadismo, as suas causas e consequências. Ademais, tem como proposta apontar as ações estatais de proteção destes povos, com base na discriminação e na segregação que sofrem diante da sociedade civil, bem como as políticas públicas capazes de efetivar o direito fundamental social à moradia, como um pressuposto para a dignidade humana destes grupos, através de prestações positivas, respeitando as suas práticas e opções culturais. A metodologia utilizada para a realização da pesquisa foi teóricobibliográfica e o método dedutivo.
\end{abstract}

PALAVRAS-CHAVE: Direito à Moradia; Direito Fundamental Social; Ciganos; Cultura Cigana; Nomadismo.

\section{GYPSY CULTURE: THE PRACTICE OF NOMADISM AND THE CONCRETIZATION OF THE RIGHT TO HOUSING}

\begin{abstract}
This article aims to analyse the history and general aspects of the culture of Gypsy people, especially the practice of nomadism, its causes and consequences. Furthermore, it is proposed to evaluate the state actions of protection of these peoples, based on discrimination and segregation that suffer before civil society, as well as public policies capable of effecting the fundamental social right to housing, as an assumption for Human dignity of these groups, through positive benefits, respecting their cultural practices and options. The methodology used for conducting the research was theoretical-bibliographic and the deductive method.
\end{abstract}

KEY-WORDS: Right to housing; Fundamental Social Law; Gypsies; Gypsy culture; Irregular occupations; Nomadism.

\footnotetext{
* Mestranda em Proteção dos Direitos Fundamentais pelo Programa de Mestrado em Direito da Universidade de Itaúna - UIT, com área de concentração na linha de pesquisa Direito Processual Coletivo e Efetividade dos Direitos Fundamentais. Pós-graduada em Direito Processual pela Universidade Pontifícia Católica de Minas Gerais (2017). Pós-graduada em Direito Processual Civil pela Universidade Anhanguera-Uniderp (2014). Graduada em Direito pela Faculdade de Direito e Ciências Sociais do Leste de Minas (2011). E-mail: rayssarm@hotmail.com.

** Doutora em Direito Público pela Pontifícia Universidade Católica de Minas Gerais. Mestre em Direito Internacional e Comunitário pela Pontifícia Universidade Católica de Minas Gerais (2006). Especialista em Direito Processual pelo IEC/PUCMINAS(2003). Graduada em Direito pela Pontifícia Universidade Católica de Minas Gerais (2006). Professora Adjunta do Departamento de Direito Público da Faculdade de Direito da Universidade Federal de Minas Gerais e professora da Pós-graduação Stricto Sensu da Universidade de Itaúna. E-mail: carlavolpini@hotmail.com
}

Revista Brasileira de Direitos e Garantias Fundamentais | e-ISSN: 2526-0111 | Salvador | v. 4 | n. 1 | p. 169 - 184 | Jan/Jun. 


\section{INTRODUÇÃO}

De acordo com a história, os povos ciganos "sempre viveram estigmatizados e numa profunda insegurança” (MEDERIROS e BATISTA, 2015, p.204) nas sociedades orientais e ocidentais, considerados criminosos e responsabilizados pela propagação de doenças. Por onde passam despertam curiosidade e também muitos preconceitos, que culminam com a sua segregação social e espacial.

Atualmente, as pesquisas que abrangem os ciganos estão em construção e diversos pontos ainda não foram abordados, assim o objetivo geral do presente artigo é apontar maneiras de efetivar o direito fundamental social à moradia adequada aos cidadãos que compõem as comunidades ciganas, garantindo proteção às suas práticas culturais, sobretudo o estilo de vida nômade, bem como contemplando o grupo com maior visibilidade.

Importante frisar que o nomadismo pode ser opcional, proveniente de um instinto de liberdade, ou compulsório, nos casos de exclusão dos povos ciganos por preconceito do restante da sociedade não-cigana. Neste sentido, é importante assegurar, àqueles que desejarem seguir com a prática do nomadismo, condições adequadas para a realização de acampamentos ciganos em todo território nacional e, aos que pretenderem se fixar em determinada localidade, que haja políticas públicas específicas e eficazes para a concretização do direito à moradia digna.

Os objetivos específicos compreendem um estudo acerca da cultura dos povos ciganos, com ênfase na prática do nomadismo, passando por um breve histórico sobre o surgimento destes grupos e fazendo referência aos principais institutos de proteção nacional. Em seguida, será analisado o direito social à moradia e o seu caráter de fundamental, sendo a sua efetivação um dever prestacional do Estado.

A escolha do tema justifica-se pela necessidade de se estabelecer garantias aos povos ciganos, como a promoção de suas práticas culturais, o empoderamento de sua história e estilo de vida, a mudança de paradigmas de inferiorização e exclusão de seus membros e, sobretudo, como abordagem principal deste artigo, o direito ao acesso à terra e a regularização de suas ocupações, visto que o direito social à moradia é inerente a todos os cidadãos, sem exceções.

A metodologia utilizada na realização do presente trabalho foi teórico-bibliográfica, com procedimento metodológico dedutivo, buscando embasamento em doutrinas de 
referência nacional e documentos internacionais, visando esclarecer alguns conceitos relacionados ao direito fundamental à moradia, à cultura dos povos ciganos e às ocupações irregulares, com o fito de compreender e elaborar uma conclusão para o tema discutido. Além das doutrinas, foram analisadas a Constituição Federal de 1988 e a legislação infraconstitucional referente à matéria.

\section{ASPECTOS GERAIS ACERCA DA CULTURA CIGANA}

Antes de adentrar no estudo da cultura das comunidades ciganas, cumpre explicar a diferença entre minorias e grupos vulneráveis, visto que tal distinção se faz necessária para a aplicação de políticas públicas. De certo, as minorias e os grupos vulneráveis possuem semelhanças, como a violência e a dominação sofridas, à inacessibilidade ao poder e a segregação social, no entanto são institutos diferentes.

As minorias são representadas basicamente por três elementos: numérico, nãodominância e solidariedade entre seus membros. É preciso que as minorias sejam formadas por uma quantidade pequena de pessoas, como o próprio nome sugere, ou, pelo menos, por um número ínfimo em relação aos que representam os grupos vulneráveis. Essa minoria numérica é a característica que leva o grupo à uma posição política desprivilegiada no Estado Democrático de Direito, visto que a clássica democracia representativa é conquistada pela predominância do desejo da maioria. Contudo, isto não significa dizer que um "grupo pequeno” por si só caracteriza uma minoria. É preciso somar este fato aos elementos de nãodominância e de solidariedade entre os membros, que visa preservar as características próprias do grupo e manter as suas peculiaridades. Justamente estas diferenças é que provocam a estereotipia $^{1}$ e a invisibilidade por parte da sociedade e do Estado.

Já os grupos vulneráveis, apesar de também serem destituídos de poder, se apresentam em grande contingente, em um número consideravelmente maior se comparados às minorias. Podemos citar, como exemplo de categorias vulneráveis, as mulheres, as crianças e os idosos, ou seja, categorias que não possuem características específicas, mas carecem de proteção por conta de suas debilidades.

Sobre essa diferenciação, Valério de Oliveira Mazzuoli explica:

\footnotetext{
${ }^{1} \mathrm{O}$ sentido que o texto pretende dar à estereótipo é de um padrão preestabelecido e de um pensamento compartilhado pelo senso comum, baseados na falta de conhecimento sobre determinado assunto, geralmente preconceituoso e inverídico.
} 
Minorias são grupos de pessoas que não tem a mesma representação política que os demais cidadãos de um Estado ou, ainda, que sofrem histórica e crônica discriminação por guardarem entre si características essenciais à sua personalidade que demarcam a sua singularidade no meio social, tais como etnia, nacionalidade, língua, religião ou condição pessoal; trata-se de grupos de pessoas com uma identidade coletiva própria, que os torna “diferentes” dos demais indivíduos no âmbito de um mesmo Estado [...]. Grupos vulneráveis, por sua vez, são coletividades mais amplas de pessoas que, apesar de não pertencerem propriamente às "minorias”, eis que não possuidoras de uma identidade coletiva específica, necessitam, não obstante, de proteção especial em razão de sua fragilidade ou indefensabilidade. (MAZZUOLI, 2016, p.263)

É possível observar, com base nesses conceitos, que a sociedade cigana compõe uma minoria, cujos direitos são deixados de lado pela apreciação do Pode Público. Vale dizer que, o Estado tem o dever de implantar políticas públicas de “discriminação positiva”, com o fito de promover o combate à não-dominância das comunidades ciganas, elevando à democracia a um grau qualitativo, não apenas quantitativo.

Apesar de decorridos tantos anos desde a ‘ocidentalização' dos povos ciganos, e mesmo com as fortes influlências externas que sofreram e ainda sofrem da sociedade dos gadjés (não-ciganos), os indivíduos ciganos foram capazes de construir e manter um sistema próprio de organização de suas comunidades. A globalização, o capitalismo, o consumismo e o avanço da tecnologia não foram capazes de corromper as práticas culturais da etnia cigana, visto que são pautadas em tradições e crenças muito fortes, como a valorização dos membros mais velhos, a virgindade da mulher até o casamento e o respeito pelo código próprio. Marta Vanelli ensina que

\begin{abstract}
a forte identidade étnica cigana por um lado é um fator positivo, de outro, provoca a sua desvinculação social, política, religiosa, cultural e econômica da sociedade dos gadjés, por vezes, em contraposição ao estabelecido pela Constituição Federal e demais legislações. Basta considerar, por exemplo, a recusa dos ciganos nômades em fazer uso do judiciário por reconhecerem como legítimo o julgamento emanado pelo Kriss, um conselho cigano composto por anciões do sexo masculino. Portanto, viver em um sistema paralelo e sectário impulsiona duas formas de exclusão social aos povos ciganos nômades: a primeira, advinda pelos próprios ciganos, que da sociedade gadjé se distanciam por não comungarem as mesmas concepções de vida, e a segunda, pela estigmatização atribuída pelo Estado e pela população não-cigana, por desconhecerem os modos de vida, costumes, culturas e tradições dos povos ciganos. (VANELLI, 2010, p.260)
\end{abstract}

A língua é um dos elementos mais importantes da tradição cigana. Incrivelmente, esses grupos conseguiram repassar os seus costumes e o seu forte misticismo, através dos séculos, apenas por meio da oralidade, e o seu idioma é o grande responsável pela perpetuação das tradições. 
Apesar das dificuldades em motivar e datar as primeiras migrações, a comunicação entre os ciganos é um dos pontos facilitadores na reconstrução da sua trajetória histórica pelo mundo.

\subsection{Breve histórico sobre os grupos ciganos}

A ‘Ciganologia’ surgiu na Europa no século XIX e se consolidou no século XX. Os seus estudos são responsáveis pelo levantamento, registro e compreensão das práticas tradicionais da cultura cigana.

De acordo com as principais pesquisas, existe mais de uma teoria para explicar o surgimento do povo Rom (povo cigano). É difícil afirmar a origem cigana com convicção, uma vez que este povo possui tradições orais e suas histórias são apenas contadas. Luciana de Assiz Garcia explica que

A grande maioria dos estudiosos acreditam que a origem dos ciganos está na região do Punjab, no noroeste da Índia, isto devido a vários elementos interiores e exteriores, tais como, as roupas, a língua, o nomadismo, as práticas de adivinhação como a quiromancia, a cor da pele, rituais antes e após o casamento, a valorização da virgindade antes do casamento bem como outros elementos que os identificam com alguns povos da Índia. (GARCIA, 2014, p.6)

No Brasil, segundo Marta Vanelli,

os primeiros povos ciganos se estabeleceram em Pernambuco, Bahia e em Minas Gerais, por terem sido deportados de Portugal, e outra parcela acompanhou a Corte Portuguesa, com a vinda de D. João VI, para servir de distração, pois eram artistas teatrais. Assim, iniciaram o ciclo de migrações no território brasileiro nas florestas, nos centros urbanos e nos espaços rurais dos engenhos, com a tribo Calon, de Portugal e da Espanha, e os Rom, da Iugoslávia, Romênia e Hungria. Conforme dados da Associação de Preservação da Cultura Cigana - APRECI-SP existem no Brasil um milhão e duzentos mil ciganos e no estado de São Paulo estima-se cerca de trezentos mil (APRECISP, 2009). Mas, na realidade, o Brasil não possui dados oficiais sobre a população cigana, quiçá o fluxo migratório das tribos nômades. (VANELLI, 2010, 258/259)

De certo, a história do povo cigano é marcada por dor, maus tratos, perseguição e ódio. Até mesmo em nações consideradas liberais, como a Suécia, foram considerados indivíduos malditos e tratados com brutalidade. Na França, os homens eram exterminados e as mulheres tinham suas cabeças raspadas. Na Alemanha foram perseguidos como animais, torturados e queimados (GARCIA, 2014, p.8/9). 
Diante da constatação de tantas injustiças cometidas contra seres humanos inocentes, apenas por puro preconceito e desconhecimento de seu estilo de vida e práticas culturais, é preciso resgatar a dignidade dos povos ciganos, através de institutos de proteção, conscientização e empoderamento, obrigatoriamente criados pelos Governos.

\subsection{Proteção nacional à cultura e aos direitos ciganos}

Considerando as intensas discussões e reflexões acerca do multicultiralismo e da grande variedade de culturas nas sociedades contemporâneas, é espantoso saber que o governo brasileiro admite a falta de dados sobre os grupos ciganos, justificando, assim, a ausência de políticas públicas eficazes que beneficiem estes cidadãos.

Faisal Bhabha ensina que o multiculturalismo é uma relação entre o Estado e os seus indivíduos, sendo que o exercício da cidadania oferece equidade de direitos e responsabilidades. Ao participarem ativamente dos assuntos civis, os cidadãos afirmam esses direitos e fortalecem a democracia do seu Estado, assegurando que uma cidadania multicultural, integrada e inclusiva seja a herança de todos (2009, p.47) ${ }^{2}$.

Com a intenção de inserir os direitos dos grupos ciganos nas políticas estatais e garantir o exercício da cidadania a todos os seus integrantes, diversos movimentos sociais reinvidicam a inclusão do estudo da cultura dos povos ciganos e do mapeamento dos acampamentos Calon no censo do IBGE (Instituto Brasileiro de Geografia e Estatística).

Em maio de 1993, com o advento da Lei Complementar $n^{\circ} 75^{3}$, os povos ciganos foram incluídos na classificação de “minorias étnicas” do artigo $6^{\circ}$, elencando o rol de grupos vulneráveis, juntamente com as comunidades indígenas, para que o Ministério Público Federal passasse a promover a proteção e a defesa dos seus interesses indisponíveis, através de inquérito civil ou de ação civil pública. Nas palavras de Gregório Assagra de Almeida “[...]

\footnotetext{
2 "Multiculturalism is a relationship between Canada and the Canadian people. Our citizenship gives us equal rights and equal responsibilities. By taking an active part in our civic affairs, we affirm these rights and strengthen Canada ' democracy, ensuring that a multicultural, integrated and inclusive citizenship will be every Canadian s inheritance. The time has come for Canadians to be weaned off the teat of multiculturalism as a primary source of sustenance and self-identity. Surely, in the 21st century, we are more than the sum total of our diverse parts and hyphenated definitions.” (BHABHA, 2009, p.47)

${ }^{3}$ Art. $6^{\circ}$ Compete ao Ministério Público da União:

VII - promover o inquérito civil e a ação civil pública para:

c) a proteção dos interesses individuais indisponíveis, difusos e coletivos, relativos às comunidades indígenas, à família, à criança, ao adolescente, ao idoso, às minorias étnicas e ao consumidor;
} 
a concessão dessa atribuição ao Ministério Público por lei infraconstitucional está em perfeita consonância com a Constituição Federal (art. 129, III e IX, da CF)” (2008, p.558).

Contudo, os avanços nesta seara foram muito discretos e apenas em 2002 surgiram as primeiras discussões sobre a inclusão da etnia cigana aos direitos sociais (educação, saúde, assistência social e previdenciária).

Existem apenas três ações estatais realizadas em nível nacional que garantem aos ciganos o acesso à direitos sociais. O primeiro é a existência de um Dia Nacional do Cigano (24 de maio) ${ }^{4}$, o segundo, a criação do SEPPIR (Secretaria de Políticas de Promoção da Igualdade Racial) ${ }^{5}$ e o terceiro, o Guia de Políticas Públicas para Povos Ciganos ${ }^{6}$. As demais ações são regionais e causam pouco impacto na sociedade.

O Guia de Políticas Públicas para Povos Ciganos é dividido em quatro grandes eixos. O primeiro, intitulado 'Direitos Humanos', visa promover uma mobilização nacional em prol do registro civil e da documentação básica dos ciganos, além da capacitação de defensores públicos para atender os direitos das comunidades, a segurança nos acampamentos e a mediação de conflitos. O segundo, 'Políticas Sociais e de Infraestrutura', elenca diversos programas do Estado em prol da efetivação dos direitos sociais ciganos. O terceiro, 'Políticas Culturais', inclui, entre outras coisas, premiação para eventos de cultura cigana. E, por fim, o quarto eixo, e mais importante para o presente trabalho, trata do “Acesso à Terra” e estabelece os requisitos de Regularização Fundiária para fins de moradia, garantindo condições adequadas para a realização de acampamentos ciganos em todo território nacional.

Um dado importante é que, por conta da prática do nomadismo, a maioria dos ciganos não possui registro de nascimento ou qualquer outro tipo de documentação civil (RG e CPF, por exemplo), o que dificulta ou até impede o atendimento em hospitais e postos de saúde, a matrícula das crianças na escola e a conquista de empregos. Ressalte-se que, pela ausência de documentos, os ciganos não são eleitores e, portanto, não atraem o interesse dos governantes em ofertá-los melhorias na qualidade de vida. Sobre o tema, Marta Vanelli discorre:

\footnotetext{
${ }^{4}$ No Brasil o dia Nacional do Cigano é comemorado no dia 24 de Maio. Existe ainda um dia Internacionaciol do Cigano, 8 de Abril. O objetivo destas datas é celebrar as tradições ciganas e chamar a atenção para as dificuldades e segregação social que a comunidades ciganas sofrem.

${ }^{5}$ http://www.seppir.gov.br/

${ }^{6}$ http://www.seppir.gov.br/portal-antigo/.arquivos/guia-de-politicas-publicas-para-povos-ciganos/view
} 
[...] a mais problemática situação dos ciganos nômades é o seu reconhecimento como indivíduo, já que parcela desta população simplesmente não possui certidão de nascimento, o principal registro civil ao acesso aos direitos e à cidadania na sociedade gadjé, por uma exigência legal, que não contempla a realidade das tribos nômades: ter um endereço fixo. Desde 2005, existe a reivindicação dos povos ciganos sobre a revisão da Lei 6.015/73, que define as regras de registro público, mas ainda sem progresso (SEDH, 2010). Não possuir um endereço fixo, além do impedimento ao registro civil de nascimento, impacta aos que possuem outros enfrentamentos, como o acesso aos benefícios dos programas federais à elevação da renda familiar e aos serviços de saúde, exceto em casos notificados como de emergência. Tudo porque na sociedade gadjé os ciganos nômades são socialmente invisíveis, o que demonstra a discriminação étnica. (VANELLI, 2010, p.263)

Corroborando este entendimento, Télia Resende de Sousa Lima explica que

mesmo para a obtenção dos benefícios mencionados pela SEPPIR para inclusão das populações de baixa renda, que constam como políticas públicas para ciganos, é necessário possuir um endereço fixo, o que contrasta com o nomadismo dos indivíduos ciganos aos quais interessam essas políticas. Projetos como a confecção de um Cartão Educação e Cartão Saúde, para que povos itinerantes possam ser matriculados em escolas e atendidos em hospitais, sem a exigência de endereço, têm sido muito discutidos, mas sem notícias de que tenham auferido resultado prático. (LIMA, 2014, p.233)

Em maio de 2013, aconteceu em Brasília o I Encontro Nacional dos Povos Ciganos, que culmuniou com a elaboração do Relatório Executivo Brasil Cigano ${ }^{7}$. No decorrer do evento, foram constituídos Grupos de Trabalho para discussão de propostas, como construir estratégias para garantir participação dos Povos Ciganos em instâncias de controle social, como os conselhos municipais, estaduais e nacionais; viabilizar audiências públicas para debater a garantia de direitos e acesso às políticas dos Povos Ciganos; garantir que o MEC inclua conteúdo adequado sobre os Povos Ciganos nos materiais didáticos; estabelecer escolas específicas para Povos Ciganos; implementar projetos de Inclusão Digital; garantir a geração de emprego e renda; incluir os Povos Ciganos nos materiais institucionais da SEPPIR e do Governo Federal em geral; criar campanha de combate ao preconceito aos Povos Ciganos; e garantir infraestrutura e segurança para os acampamentos ciganos (2013, p.39/40).

Apesar das diversas propostas com o intuito de melhorar a qualidade de vida dos povos ciganos, nenhuma tratava diretamente do direito social à moradia. Aliás, a palavra “moradia” sequer foi citada no relatório, sendo que a única menção referente aos direitos fundiários foi sobre a possível análise de regularização de territórios, que nunca foi efetivada.

\footnotetext{
${ }^{7}$ http://www.seppir.gov.br/comunidades-tradicionais/relatorio-executivo-brasil-cigano.pdf
} 
Ainda acerca das políticas públicas implementadas em prol dos povos ciganos, Télia

Resende de Sousa Lima afirma que

\begin{abstract}
é possível detectar que a única política específica para ciganos que alcançou caráter prático é relacionada a cultura, muito embora a introdução ao guia relate como principais demandas "educação, saúde, registro civil, segurança, direitos humanos, transferência de renda e inclusão produtiva”. As demais políticas públicas que constam no guia não são específicas a povos ciganos, mas programas direcionados a populações de baixa renda em geral, como Bolsa Família, Minha Casa, Minha Vida, Luz para Todos etc. O programa específico que já se encontra em prática denominase Prêmio Culturas Ciganas, e consiste em um concurso cultural que teve sua primeira edição em 2007 e busca premiar indivíduos ou instituições que elaborem o melhor trabalho que "contribua ao fortalecimento das expressões culturais ciganas". Há também o programa Pontos de Cultura, destinado a pessoas jurídicas de direito privado sem fins lucrativos que se interessem em promover convênios com o governo para fomento e conformação de pontos de cultura em seus territórios. (LIMA, 2014, p.232)
\end{abstract}

Neste sentido, é possível notar que o Guia de políticas públicas para povos ciganos não prevê medidas com a intenção de concretizar o direito social à moradia para os cidadãos ciganos que desejam se fixar (tornarem-se 'sedentários') ou mesmo para receber e integrar os que, pelo instinto de liberdade, preferem continuar exercendo a prática do nomadismo. A introdução do guia sequer cita o direito à moradia no seu rol de direitos sociais, sendo que apenas o programa 'Minha Casa, Minha vida' engloba os direitos habitacionais dos ciganos, visto que os mesmos geralmente possuem baixa renda. No entanto, não existem programas específicos que atendam às demandas e necessidades peculiares desses indivíduos, obrigandoos a se instalarem em ocupações urbanas irregulares, geralmente situadas em zona de risco ambiental, segregadas do restante da sociedade e sem o mínimo existencial necessário para a garantia da dignidade da pessoa humana.

\title{
2.3 A prática do Nomadismo e as suas consequências
}

Os fatos mostram e os próprios membros dos grupos ciganos afirmam que a prática do nomadismo não se trata somente de uma questão de escolha ou costume, mas o seu hábito pode ser resultado do preconceito, das perseguições e da exclusão a que os ciganos são submetidos.

Atualmente a grande maioria dos ciganos vive um estilo de vida denominado 'sedentário', isto é, abandonaram o nomadismo e se fixaram. No entanto, há divergência 
dentro do próprio grupo minoritário, visto que os ciganos considerados tradicionais (pela prática do nomadismo) questionam se a identidade cigana dos ‘sedentários’ é autêntica.

Esse comportamento divergente dentro de um próprio grupo minoritário é explicado pelo autor canadense Faisal Bhabha como um fenômeno que pode gerar dois pontos de vista. O primeiro é denominado Exclusão e significa que parte do grupo deseja ou precisa se separar para preservar e melhorar o seu status através do estabelecimento de esferas exclusivas de autoridade. Enquanto outra parte é marcada pela caracterísctica da integração, chamada de Assimilação pelo autor, e trata-se do interesse ou objetivo individual de alguns membros de serem admitidos como iguais na sociedade convencional (2009, p. 48/49) ${ }^{8}$.

No caso dos ciganos, especificamente, nota-se que os indivíduos que ainda exercem o nomadismo carregam uma característica de Exclusão, seja pelo desejo de peregrinar, baseado no sentimento de liberdade ou, na maioria das vezes, por uma necessidade fundamentada pela segregação social. E os ciganos 'sedentários', aqueles que vivem em habitações fixas e conseguem se integrar aos hábitos cotidianos convencionais da sociedade, se enquadram no conceito de Assimilação.

De acordo com o Presidente da Embaixada Cigana do Brasil "Phralipen Romane”, Nicolas Ramanush, o nomadismo no Brasil é uma característica atribuída especificamente aos grupos Calon, justificado por dois fatores: primeiramente, o seu sustento vem do comércio que necessita de mobilidade e, em segundo lugar, por não encontrarem políticas públicas integrativas, mesmo quando pretendem se estabelecer em determinada localidade.

O fato é que, independentemente da motivação que leva os ciganos nômades a se deslocarem de lugar em lugar, este hábito gera um problema pelas cidades onde passam: as ocupações irregulares. Seja por falta de opção ou pelas dificuldades, as famílias optam pela ocupação de terrenos alheios abandonados ou subutilizados, geralmente situados em zonas de risco ambiental, onde constroem habitações informais como barracas.

Sobre os reflexos e consequências das ocupações irregulares, Renata Lima, Samira Haddad e Maria Aparecida Valério prelecionam:

\footnotetext{
8 “These opposing views encapsulated the tension underlying multicultural accommodation between the desire of minority groups to preserve and to enhance their status through the establishment of exclusive spheres of authority, and the goal of many individual group members to gain admittance as equals in mainstream society. These two types of interests-the group's desire to separate and the individual's desire to integrate-are not as categorical or clearly distinguishable as they may seem.” (BHABHA, 2009, p.48/49)
} 
A falta de moradia impulsiona o acesso informal ao solo, sendo a proliferação de habitações irregulares agravada pela falta de políticas habitacionais adequadas para atender à população necessitada. Os reflexos sociais e econômicos do referido problema são facilmente identificados através das flagrantes situações de exclusão e desigualdade social. Dentre outros, pode-se destacar a discriminação, desemprego, violência nos centros urbanos, a privação de acesso aos equipamentos públicos que garantem a saúde e a educação, além do colapso dos sistemas de transportes coletivos e congestionamentos no trânsito. Nessas ocupações, a falta de infraestrutura e atenção política são palco de inúmeros problemas como o aumento de processos erosivos, assoreamentos dos rios e impermeabilização do solo como fator desencadeador das inundações, deslizamento de encostas, soterramentos, e proliferação de doenças. Tais lugares são cenários de pobreza e miséria fomentando todo tipo de violência. (LIMA, HADDAD e VALÉRIO, 2017, p.17/18)

Ocorre que, assim como outros tantos direitos sociais, o direito à moradia adequada possui previsão constitucional e a sua concretização pode ser exigida com base no princípio da dignidade da pessoa humana e no objetivo fundamental de erradicação da pobreza e da marginalização e da redução das desigualdades sociais ${ }^{9}$.

\section{DIREITO À MORADIA: DIREITO CONSTITUCIONAL GARANTIDO A TODOS}

O direito fundamental à moradia está inserido na Declaração Universal dos Direitos Humanos desde 1948 e no artigo $6^{\circ}$ da Constituição Federal do Brasil desde a inserção da Emenda n²6/2000 no texto constitucional.

O seu conceito está intimamente relacionado a um padrão de vida adequado, ou seja, a qualidade das moradias, que deve garantir o mínimo existencial necessário para assegurar este direito social basilar, visto que se trata de um bem jurídico indispensável à dignidade da pessoa humana. O direito de habitar é primordial e religioso, no sentido literal da origem etimológica da palavra religião, isto é, “religa” o homem aos demais direitos fundamentais que gerem a vida individual e em comunidade. Todos os outros direitos fundamentais sociais estão diretamente ligados ao direito à moradia digna e adequada, como os direitos à segurança, à alimentação, à educação, ao lazer e ao transporte público e coletivo.

\subsection{Dever do Estado na concretização do direito à moradia}

Existe uma obrigatoriedade do Estado em promover a efetivação dos direitos fundamentais, especialmente, para o presente trabalho, do direito à moradia digna e adequada

\footnotetext{
${ }^{9}$ Constituição Federal - Art. $3^{\circ}$. Cosntituem objetivos fundamentais da República Federativa do Brasil: III - erradicar a pobreza e a marginalização e reduzir as desigualdades sociais e regionais.
} 
para os indivíduos que integram grupos ciganos. Assim, deve ser travada uma luta pela busca de um ambiente urbano igualitário, com oportunidades equitativas para todos, sem a segregação dos hipossuficientes, na medida da desigualdade de cada pessoa, tomando as providências necessárias para assegurar a concretização desse direito coletivo, sem afetar ou oprimir as práticas Culturais subjetivas. Sobre o dever de igualdade, ensina Robert Alexy que:

\begin{abstract}
Ele exige que toda norma jurídica seja aplicada a todos os casos que sejam abrangidos por seu suporte fático, e a nenhum caso que não o seja, o que nada mais significa que dizer que as normas jurídicas devem ser cumpridas. Mas o dever de obedecer às normas jurídicas é algo que elas mesmas já afirmam, na medida em que expressam um dever-ser. Nesse sentido, o dever de igualdade na aplicação da lei exige apenas aquilo que já é de qualquer forma aplicável se as normas jurídicas são válidas. Ele reforça a vinculação dos órgãos de aplicação do direito às normas criadas pelo legislador, sem estabelecer qualquer requisito substancial para essas normas, ou seja, sem vincular o legislador. $\mathrm{O}$ legislador pode discriminar como bem lhe aprouver; desde que suas normas discriminatórias sejam observadas em todos os casos, o dever de igualdade na aplicação da lei terá sido satisfeito. (ALEXY, 2008, p.394).
\end{abstract}

Isso significa que, a partir do momento que a Constituição Federal Brasileira prevê em seu artigo $5^{\circ}, \S 1 .^{\circ}$ a "aplicabilidade imediata das normas definidoras dos direitos e garantias fundamentais”, chama para si o dever de cumprir a referida norma e satisfazer as demandas de cada indivíduo, sempre de maneira igualitária, de modo que supra as necessidades de todos.

E não quer dizer que apenas os direitos elencados no artigo $5^{\circ}$ da Constituição Federal são alcançados por tal norma, uma vez que o seu rol não é taxativo e é possível encontrar direitos fundamentais espalhados por toda $\mathrm{CR} / 88$, além de documentos internacionais que o Brasil é signatário. Neste sentido, a moradia, como um direito fundamental social com previsão constitucional é abarcada pela obrigatoriedade prestacional do Estado.

É importante também esclarecer o fato dos direitos sociais previstos no caput do artigo $6^{\circ}$ serem considerados fundamentais. Parte da doutrina considera os direitos sociais como direitos fundamentais propriamente ditos, enquanto outra parte considera que estes são direitos fundamentais atribuídos, isto é, que apesar de não serem propriamente fundamentais por não estarem no rol no artigo $5^{\circ}$, possuem algum vínculo com estas normas que garanta 0 seu caráter de fundamental.

Sobre a fundamentalidade dos direitos sociais e a sua localização topográfica na Constituição Federal, o jurista Ingo Wolfgang Sarlet ensina: 
A Constituição de 1988 - e isto pode ser tido como mais um de seus méritos acolheu os direitos fundamentais sociais expressamente no título II (Dos Direitos e Garantias Fundamentais), concedendo-lhes capítulo próprio e reconhecendo de forma inequívoca o seu "status" de autênticos direitos fundamentais, afastando-se, portanto, da tradição anterior do nosso constitucionalismo, que, desde a Constituição de 1934, costumava abrigar estes direitos (ao menos parte dos mesmos), no título da ordem econômica e social, imprimindo-lhes reduzida eficácia e efetividade, ainda mais porquanto eminentemente consagrados sob a forma de normas de cunho programático. (SARLET, 2001, p.17)

Independentemente de sua classificação (fundamentais próprios ou atribuídos), os direitos sociais devem ser prestados pelo Estado, e para isso se espera uma Ação Positiva por parte dos entes públicos. Na lição de Nelson Saule Júnior:

O direito à moradia como integrante da categoria dos direitos econômicos, sociais e culturais, para ter eficácia jurídica e social, pressupõe a ação positiva do Estado, através da execução de política públicas, no caso em especial da promoção da política urbana e habitacional. Com as constituições contemporâneas, a emergência de um significativo número de normas de caráter programático, referente aos direito humanos de segunda geração foi se construindo uma ruptura à teoria clássica sobre a aplicabilidade das normas constitucionais, visando a efetivação dos direitos econômicos, sociais e culturais, de modo a conferir a esses direito o grau de aplicação imediata e direta. (SAULE JUNIOR, 1997, p.5).

Diferentemente dos direitos de liberdade, cuja efetivação só exige que o Poder Estatal permaneça inerte e não interfira na esfera das decisões privadas dos indivíduos, os direitos sociais precisam da elaboração e da execução de políticas públicas, que dependem de custeio e, por isso, devem ser previamente inseridas no planejamento orçamentário do município. Para José Luis Bolzan de Morais:

\footnotetext{
Este caráter prestacional se vincula inexoravelmente à implementação de direitos sociais, econômicos e culturais através da ação política - políticas públicas - estatal. [...] a implementação dos conteúdos de direitos humanos, em particular os positivos, implicam a necessária compreensão da ação jurídica fundamentada em uma prática comprometida e assente em uma teoria engajada, onde a Constituição não seja percebida exclusivamente como uma folha de papel. (MORAIS, 2011, p.99-100)
}

Assim, permitir que o Estado faça-se omisso na prestação de suas obrigações sociais seria utilizar de argumentos vazios para reduzir as garantias constitucionais dos cidadãos. O correto seria o Estado ofertar a melhor qualidade na concretização do direito à moradia para todos, de acordo com suas peculiaridades, mas como não o faz, tem o dever de prestar pelo menos o mínimo para os cidadãos.

A Assembleia Geral das Nações Unidas, através da Declaração sobre as Cidades e outros Assentamentos Humanos no Novo Milênio, Programa Habitat III, afirma que é 
obrigatoriedade das autoridades locais desempenhar um papel eficaz no fornecimento de habitação e desenvolvimento sustentável dos assentamentos humanos. O artigo $39^{10}$ da referida declaração diz, ainda, que isto pode ser alcançado através de uma efetiva descentralização das responsabilidades, gerenciamento de políticas e tomada de decisões.

Insta frisar que, antes de tratar das questões referentes à materialização Reforma Urbana e da Urbanização consciente das cidades, de maneira interdisciplinar, é preciso que o Estado promova a regularização dos imóveis urbanos para que, assim, tornem-se visíveis e sejam atingidos pela prestação de serviços públicos. Para isso, é fundamental que os juristas procurem soluções para resolver a problemática do direito à moradia no Brasil, sobretudo, obtendo informações reais e pertinentes acerca da atual sistemática trazida pelo Estatuto da Cidade, bem como, promovendo à interação de todos os interessados no processo estatal de gestão urbana. Neste sentido, Edésio Fernandes ensina sobre as bases do novo marco jurídicourbanístico:

\begin{abstract}
Esse desafio é especialmente significativo para os operadores do Direito: juízes, promotores, advogados, defensores públicos, registradores, estudantes de Direito, essa é uma categoria que está sendo veementemente chamada, ainda que tardiamente, para enfrentar esse enorme desafio que é materializar a ordem jurídicourbanística consolidada pelo Estatuto da Cidade e, assim, contribuir com outros atores no sentido da promoção da reforma urbana no Brasil. Num primeiro momento, isso exige da parte dos operadores do Direito que obtenham informação objetiva sobre essa nova ordem jurídica, seus pressupostos, seus princípios, bem como seus institutos, mecanismos e processos. Em um segundo momento, é necessária a promoção de debates que promovam uma análise crítica acerca das possibilidades dos novos institutos, estratégias e processos de gestão urbana trazidos pelo Estatuto da Cidade. E, em um terceiro momento, talvez o maior desafio de hoje para os juristas brasileiro seja o de construir uma doutrina e uma jurisprudência consistentes, sólidas, construtivas e pró-ativas, permitindo que todos os princípios da nova ordem jurídico-urbanística sejam efetivamente materializados. (FERNANDES, 2009, p.3).
\end{abstract}

\footnotetext{
${ }^{10}$ 39- Resolvemos además habilitar a las autoridades locales, a las organizaciones no gubernamentales y a otros asociados en el Programa de Hábitat, dentro del régimen jurídico de cada país y de acuerdo con sus condiciones, para desempeñar un papel más eficaz en el suministro de viviendas y en el desarrollo sostenible de los asentamientos humanos. Esto puede lograrse mediante una descentralización eficaz, cuando proceda, de las responsabilidades, la gestión de políticas y la adopción de decisiones, así como recursos suficientes, incluso, cuando sea posible, otorgando facultades de recaudación de ingresos a las autoridades locales, mediante la participación y la democracia local, y mediante la cooperación y las asociaciones internacionales. En particular, debe garantizarse un papel efectivo de las mujeres en la adopción de decisiones del gobierno local, si es necesario mediante mecanismos apropiados. En este contexto, acordamos intensificar nuestro diálogo, siempre que sea posible, inclusive mediante la Comisión de Asentamientos Humanos, en relación con todas las cuestiones correspondientes a la descentralización eficaz y al fortalecimiento de las autoridades locales, en apoyo de la ejecución del Programa de Hábitat, de conformidad con el marco jurídico y las políticas de cada país.
} 
Portanto, resta inegavelmente demonstrado, o dever do Estado no cumprimento imediato e direto de normas de direito fundamental, concretizando o direito à moradia adequada para os cidadãos, considerando as demandas particulares de cada grupo e preservando as carasterísticas culturais de todos os povos, especialmente dos ciganos, para este trabalho.

\section{CONCLUSÃO}

Diante de todo o exposto no decorrer deste artigo, é possível concluir que os povos ciganos carregam uma história de estigmatização que precisa ser superada. São pessoas inocentes, que foram segregadas somente pelo seu estilo de vida diferente ou pela não aceitação de suas práticas culturais. O sofrimento destes indivíduos tem gerado graves consequências, como o afastamento dos mais jovens dos grupos e a marginalização dos acampamentos, que são montados em ocupações irregulares, geralmente em zonas de risco ambiental e permanecem invisíveis aos olhos dos governantes, sem alcançarem sequer o mínimo existencial necessário para a garantia da dignidade da pessoa humana.

É inegável que os ciganos estão atingindo certo grau de visibilidade, no entanto, os avanços ainda são muito discretos e pouco significativos perto do que precisa ser feito para garantir o seu empoderamento como cidadãos.

Conforme demonstrado, no Brasil os intitutos de proteção dos povos ciganos se resumem em um Guia de Políticas Públicas para Povos Ciganos, criado pelo SEPPIR (Secretaria de Políticas de Promoção da Igualdade Racial) e um Relatório, elaborado com base nas discussões realizadas no I Encontro Nacional dos Povos Ciganos. Contudo, não possuem uma legislação específica para tratar de suas verdadeiras demandas.

Como alternativa para solucionar o problema da deficiência de políticas públicas de moradia em prol dos povos ciganos, bem como para garantir a efetivação dos demais direitos sociais, é preciso que os movimentos sociais travem uma luta em face do Estado, reivindicando e exigindo que sejam realizadas prestações positivas, que contem com a participação popular dos diretamente interessados (ciganos) na elaboração de propostas, visto de que se trata de um dever previsto constitucionalmente.

\section{REFERÊNCIAS}

ALEXY, Robert. Teoria dos Direitos Fundamentais. São Paulo: Malheiros Editores, 2015. 
ALMEIDA, Gregório Assagra. Direito Material Coletivo: superação da summa divisio direito público e direito privado por uma nova summa divisio constitucionalizada. Belo Horizonte: Del Rey, 2008.

BHABHA, Faisal. Between Exclusion and Assimiliation: Experimentalizing Multiculturalism. 54 McGill L. J. 45, 90. HeinOnline, 2009.

FERNANDES, Edésio. A nova ordem jurídico-urbanística no Brasil. Disponível em: <file:///C:/Users/Cliente/Downloads/A_nova_ordem_juridico-urbanistica_no_Brasil.pdf> Acesso em: 15 Jun. 2017.

GARCIA, Luciana de Assiz. Análise sobre práticas tradicionais na cultura cigana, com enfoque na quiromancia e no nomadismo. II Semana de Pos-Graduação em Ciência Política: Resepensando a trajetória do Estado Brasileiro. ISSN: 2358-4165. São Carlos, 2014.

LIMA, Télia Resende de Sousa. Ciganos: breve definição e análise dos movimentos sociais e políticas públicas no Brasil até 2014. Revista Humanidades em diálogo. São Paulo, v. 6, p. 225-237, nov 2014. ISSN 1982-7547. Disponível em:

<https://www.revistas.usp.br/humanidades/article/view/106271>. Acesso em: 17 dez. 2017.

MAZZUOLI, Valério de Oliveira. Curso de Direitos Humanos. 3 ed. rev., atual. e ampl. São Paulo: Método, 2016.

MEDEIROS, Jéssica Cunha de. e BATISTA, Mércia Rejane Rangel. Nomadismo e Diáspora: sugestões para se estudar os ciganos. Revista Anthropológicas. Ano 19. 26(1):201-230, 2015.

MORAIS, Jose Luis Bolzan de. As crises do Estado e da Constituição e a Transformação Espaço-Temporal dos Direitos Humanos. 2. ed. rev. ampl. Porto Alegre: Livraria do Advogado Editora, 2011.

RAMANUSH, Nicolas. Cultura cigana, nossa história por nós - partes I e II. Embaixada Cigana do Brasil "Phralipen Romane”, 2011. Disponível em: <http: www.

embaixadacigana.com.br> Acesso em 16 Dez 2017.

SARLET, Ingo Wolfgang. Os Direitos Fundamentais Sociais na Constituição de 1988. Ano I. Vol. I. No. 1. Salvador: Revista Diálogo Jurídico, 2001.

SAULE JÚNIOR, Nelson. O direito à moradia como responsabilidade do Estado Brasiliero. Cadernos de pesquisa $\mathrm{n}^{\circ}$ 7, 1997.

VANELLI, Marta. Nomadismo cigano: migração dos excluídos. Cadernos do CEOM - Ano 23, n. 32 - ETINICIDADES. 2010. 